\title{
A New Quadrannulate Species of Orobdella (Hirudinida: Arhynchobdellida: Orobdellidae) from Pingtung, Taiwan
}

\author{
Takafumi Nakano ${ }^{1,3}$ and Yi-Te Lai ${ }^{2}$ \\ ${ }^{1}$ Department of Science Education, Graduate School of Education, Hiroshima University, \\ Higashihiroshima, Hiroshima 739-8524, Japan \\ E-mail: tnakano@hiroshima-u.ac.jp \\ ${ }^{2}$ Department of Life Science, National Taiwan University, No. 1, Roosevelt Road, Section 4, Taipei 106, Taiwan \\ ${ }^{3}$ Corresponding author
}

(Received 17 August 2017; Accepted 12 October 2017)

http://zoobank.org/90220F49-CD28-47AB-A627-9C4C8682F50E

\begin{abstract}
A quadrannulate leech species, Orobdella meisai sp. nov., from southern Taiwan is described. This new species is characterized by its camouflage coloration, which is unique among the known Orobdella species. Orobdella meisai is the second species of the genus to be described from Taiwan. Phylogenetic analyses using nuclear 18S rRNA, histone H3, mitochondrial cytochrome $c$ oxidase subunit I, tRNA ${ }^{\text {Cys }}$, tRNA ${ }^{\text {Met }}, 12 S$ rRNA, tRNA ${ }^{\text {Val }}, 16 S$ rRNA, tRNA ${ }^{\text {Leu }}$ and NADH dehydrogenase subunit 1 markers showed that $O$. meisai and another Taiwanese species, O. ketagalan Nakano and Lai, 2012, formed a supported clade. According to the results of the morphological examination and the phylogenetic position of $O$. meisai, morphological-phylogenetic relationships of this species and close congeners are briefly discussed.
\end{abstract}

Key Words: Erpobdelliformes, terrestrial, macrophagous, molecular phylogeny.

\section{Introduction}

The genus Orobdella Oka, 1895 comprises 18 known species inhabiting terrestrial habitats in the Japanese Archipelago, Korean Peninsula, Taiwan, and adjacent islets (Nakano 2017a, b); an Orobdella leech, whose taxonomic status remains uncertain, has been recorded from the Russian Far East (Gilyarov et al. 1969; Nakano 2012a). Orobdella species can be identified by the following three characteristics (Nakano 2017a): 1) the possession of a gastroporal duct, which is an accessory copulatory organ that receives a spermatophore during copulation (Nakano 2017b); 2) mid-body somite annulation that can be subdivided into quadrannulate (four annuli per one somite; ten species), sexannulate (six annuli; six species), and octannulate (eight annuli; two species); and 3) the body length of mature individuals, grouped into small (the body length is $\sim 5 \mathrm{~cm}$; five species), middle (reaching $\sim 10 \mathrm{~cm} ; 11$ species), and large types (reaching $\sim 20 \mathrm{~cm}$; two species). Whereas only quadrannulate species are assigned to the small type, the two octannulate species are designated large types (Nakano 2017a, b).

Orobdella leeches are particularly diversified in the Japanese Archipelago. All sexannulate, octannulate and smalltype quadrannulate species are indigenous to the archipelago (Nakano 2017a). By contrast, only one middle-type quadrannulate species O. ketagalan Nakano and Lai, 2012 is known from Taiwan (Nakano and Lai 2012); and only $O$. tsushimensis Nakano, 2011 (middle-type quadrannulate), is indigenous to the Korean Peninsula (Nakano and Seo 2012, 2014). However, several undescribed species of Orobdella have been recognized in Taiwan (Nakano and Lai 2012).

Additional Orobdella leeches, which were designated as middle-type quadrannulate, were collected from Pingtung County, Taiwan, and they are described herein as a new species. Additionally, the phylogenetic position of the new species within Orobdella was estimated using nuclear and mitochondrial genetic markers.

\section{Materials and Methods}

Sampling and morphological examination. Leeches were collected from a locality in Pingtung County, Taiwan (Fig. 1). When possible, elevation and geographical coordinates for the collection site were obtained using a Garmin eTrex $^{\circledR}$ GPS unit.

Specimens were relaxed by the gradual addition to absolute ethanol (EtOH) to freshwater, or directly fixed in absolute EtOH. For DNA extraction, botryoidal tissue was removed from the posterior part around the caudal sucker of every specimen, and then preserved in absolute $\mathrm{EtOH}$. The remainder of the body was fixed in $10 \%$ formalin and preserved in $70 \% \mathrm{EtOH}$. Four measurements were taken: body length (BL) from the anterior margin of the oral sucker to the posterior margin of the caudal sucker, maximum body width (BW), caudal sucker length (CL) from the anterior to the posterior margin of the caudal sucker, and caudal sucker 


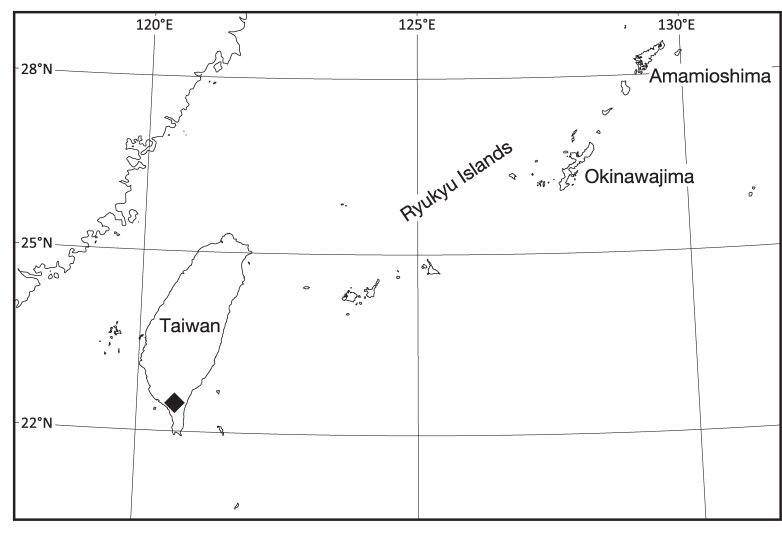

Fig. 1. Map showing the collection locality (=closed diamond) of the specimens examined in this study.

width (CW) from the right to the left margin of the caudal sucker. Examination, dissection, and drawing of the specimens were conducted using a stereoscopic microscope with a drawing tube (Leica M125). Specimens used in this study have been deposited in the Zoological Collection of Kyoto University (KUZ). The numbering convention is based on Moore (1927): body somites are denoted by Roman numerals, and the annuli in each somite are given alphanumeric designations.

PCR and DNA sequencing. Genomic DNA was extracted from botryoidal tissues preserved in absolute EtOH following the method described by Nakano (2012b). Primer sets for the PCR and cycle sequencing reactions for the nuclear 18S rRNA (18S), histone H3 (H3), and the three mitochondrial regions, i.e., 1) cytochrome $c$ oxidase subunit I (COI), 2) tRNA ${ }^{\text {Cys }}$, tRNA ${ }^{\text {Met }}, 12 S$ rRNA, tRNA ${ }^{\mathrm{Val}}$, and $16 \mathrm{~S}$ rRNA (tRNA ${ }^{\mathrm{Cys}}-16 \mathrm{~S}$ ), and 3) tRNA ${ }^{\mathrm{Leu}}$ and NADH dehydrogenase subunit 1 (tRNA ${ }^{\text {Leu}}-\mathrm{ND} 1$ ), used in this study are shown in Nakano (2016a). The PCR reactions and DNA sequencing were performed using a modified version of a method mentioned in Nakano (2012a), and the detailed conditions were identical to those in Nakano (2016a). In total, ten sequences from the unidentified Orobdella specimens were newly obtained in this study, and deposited with the International Nucleotide Sequence Database Collaboration (INSDC) through DNA Data Bank of Japan (Table 1).

Molecular phylogenetic analyses. The phylogenetic position of the newly identified Orobdella species within the genus was estimated based on the 18S, H3, COI, tRNA ${ }^{\text {Cys }}$ $16 \mathrm{~S}$, and tRNA ${ }^{\mathrm{Leu}}-\mathrm{ND} 1$ sequences. The four erpobdelliform outgroup taxa were identical to those used in the phylogenetic analyses by Nakano (2017b) (Table 1). The alignments of $\mathrm{H} 3$ and $\mathrm{COI}$ were trivial, as no indels were observed. The sequences of $18 \mathrm{~S}$, tRNA ${ }^{\text {Cys }}-16 \mathrm{~S}$, and tRNA $^{\text {Leu }}-\mathrm{ND} 1$ were aligned using MAFFT v. 7.310 L-INS-i (Katoh and Standley 2013). The lengths of the $18 \mathrm{~S}, \mathrm{H} 3, \mathrm{COI}, \mathrm{tRNA}^{\mathrm{Cys}}-16 \mathrm{~S}$, and

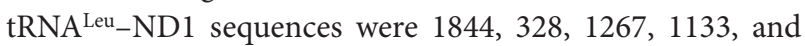
$635 \mathrm{bp}$, respectively. The concatenated sequences yielded 5207 bp of aligned positions.

Phylogenetic trees were constructed using maximum likelihood (ML) and Bayesian inference (BI). The ML phy- logeny was reconstructed using RAxML v. 8.2.8 (Stamatakis 2014) with the substitution model set as GTR $+\mathrm{I}+\mathrm{G}$, immediately after nonparametric bootstrapping (BS) was conducted with 1000 replicates. The best-fit partition scheme and the substitution model $(=\mathrm{GTR}+\mathrm{I}+\mathrm{G})$ were identified with the Akaike information criterion using PartitionFinder v. 2.1.1 (Lanfear et al. 2017) with the "greedy" algorithm: $18 \mathrm{~S}$ and $\mathrm{H} 3$ 2nd position/H3 1st position/H3 3rd position/COI 1st position/COI 2nd position/COI 3rd position/tRNA ${ }^{\text {Cys }}$, tRNA ${ }^{\text {Val }}$ and tRNA ${ }^{\text {Leu/tRNA }}{ }^{\text {Met}} / 12 S / 16 S / N D 1$ 1st position/ND1 2nd position/ND1 3rd position. BI and Bayesian posterior probabilities (PPs) were estimated using MrBayes v. 3.2.6 (Ronquist et al. 2012). The best-fit partition scheme and models for each partition were selected with the Bayesian information criterion using PartitionFinder with the "greedy" algorithm: for $18 \mathrm{~S}$ and $\mathrm{H} 3$ 1st position, $\mathrm{K} 80+\mathrm{I}$; for $\mathrm{H} 3$ 2nd position, JC+I; for $\mathrm{H} 3$ 3rd position, $\mathrm{HKY}+\mathrm{G}$; for COI 1st position, GTR $+\mathrm{G}$; for 2nd position of COI and ND1, HKY $+\mathrm{I}+\mathrm{G}$; for 3rd positions of COI and ND1, and 16S, HKY $+\mathrm{G}$; and for tRNA ${ }^{\text {Cys }}$, tRNA ${ }^{\text {Met }}, 12 \mathrm{~S}$, tRNA $^{\text {Val }}$, tRNA ${ }^{\text {Leu }}$, and ND1 1st position, GTR $+\mathrm{I}+\mathrm{G}$. Two independent runs of four Markov chains were conducted for 20 million generations, and the tree was sampled every 100 generations. The parameter estimates and convergence were checked using Tracer v. 1.6.0 (Rambaut and Drummond 2013), and the first 50001 trees were discarded based on the results.

\section{Orobdella meisai sp. nov.} (Figs 2-4)

Diagnosis. Body length of mature individual exceeding $6 \mathrm{~cm}$. Somite IV uniannulate, somites VIII-XXV quadrannulate. Clitellum in somite XI b5 to somite XIII a2. Male gonopore in somite XI b5/b6, female gonopore slightly posterior to anterior margin of somite XIII a1, behind gastropore, gonopores separated by $5+1 / 4$ annuli. Pharynx reaching to somite XV b5-b6. Gastropore conspicuous, slightly posterior to anterior margin of somite XIII a1. Gastroporal duct rudimentary tubular. Paired vasa deferentia thick. Epididymis lacking. Pre-atrial loop present. Atrial cornu lacking.

Material examined. Holotype: KUZ Z1917, dissected, collected from under a stone along the Jinshui Ying Old Trail, Fanliao, Pingtung County, Taiwan $\left(22.40730^{\circ} \mathrm{N}\right.$, $120.758568^{\circ} \mathrm{E}$; elev. $1470 \mathrm{~m}$ ) by Takafumi Nakano (TN) on 9 March 2017. Paratypes (12 specimens collected from around the type locality): KUZ Z1908 $\left(22.407^{\circ} \mathrm{N}\right.$, $120.756^{\circ} \mathrm{E}$; elev. $1490 \mathrm{~m}$ ) by Wei-Ren Liang on $26 \mathrm{Au}-$ gust 2014; KUZ Z1909-Z1910 (22.407º N, $120.756^{\circ} \mathrm{E}$; elev. $1490 \mathrm{~m}$ ) by Fu-Sheng Huang on 23 February 2014; KUZ Z1911-Z1912 (22.40824 ${ }^{\circ} \mathrm{N}, 120.75264^{\circ} \mathrm{E}$; elev. $\left.1650 \mathrm{~m}\right)$, KUZ Z1914-Z1915 $\left(22.40790^{\circ} \mathrm{N}, \quad 120.75304^{\circ} \mathrm{E} ; \quad\right.$ elev. $1620 \mathrm{~m}$ ) by Yi-Te Lai (YL) on 9 March 2017; KUZ Z1913 $\left(22.40809^{\circ} \mathrm{N}, 120.75288^{\circ} \mathrm{E}\right.$; elev. $\left.1620 \mathrm{~m}\right)$, KUZ Z1916 $\left(22.40772^{\circ} \mathrm{N}, 120.75662^{\circ} \mathrm{E}\right.$; elev. $\left.1450 \mathrm{~m}\right)$ by $\mathrm{TN}$ on 9 March 2017; KUZ Z1918-Z1919 (22.407933 $\left.{ }^{\circ} \mathrm{N}, 120.756530^{\circ} \mathrm{E}\right)$ by YL on 22 January 2017; and KUZ Z1920 $\left(22.409192^{\circ} \mathrm{N}\right.$, $120.754820^{\circ} \mathrm{E}$ ) by Kao-Shr Shiang on 9 December 2016 
Table 1. Samples used for the phylogenetic analyses. The information on the vouchers is accompanied by the INSDC accession numbers. Sequences marked with an asterisk (*) were obtained for the first time in the present study. Acronyms: KUZ, the Zoological Collection of Kyoto University; and UNIMAS, the Universiti Malaysia Sarawak.

\begin{tabular}{|c|c|c|c|c|c|c|}
\hline \multirow{2}{*}{ Species } & \multirow{2}{*}{ Voucher } & \multicolumn{5}{|c|}{ INSDC accession \# } \\
\hline & & $18 \mathrm{~S}$ & $\mathrm{H} 3$ & COI & tRNA ${ }^{\text {Cys }}-16 \mathrm{~S}$ & tRNA ${ }^{\text {Leu_ND1 }}$ \\
\hline \multicolumn{7}{|l|}{ Orobdella } \\
\hline O. meisai sp. nov. & KUZ Z1915 Paratype & LC314418* & LC314420* & LC314419* & LC314417* & LC314421* \\
\hline O. meisai sp. nov. & KUZ Z1917 Holotype & LC314423* & LC314425* & LC314424* & LC314422* & LC314426* \\
\hline O. brachyepididymis Nakano, 2016 & KUZ Z1673 Holotype & LC106319 & LC106321 & LC106320 & LC106318 & LC106322 \\
\hline O. dolichopharynx Nakano, 2011 & KUZ Z120 Holotype & AB663665 & AB698876 & AB679680 & AB679681 & AB828558 \\
\hline O. esulcata Nakano, 2010 & KUZ Z29 Holotype & AB663655 & AB698873 & AB679664 & AB679665 & AB828555 \\
\hline O. ijimai Oka, 1895 & KUZ Z110 Topotype & AB663659 & AB698877 & AB679672 & AB679673 & AB828559 \\
\hline O. kanaekoikeae Nakano, 2017 & KUZ Z1747 Holotype & LC184551 & LC184553 & LC184552 & LC184550 & LC184554 \\
\hline O. kawakatsuorum Richardson, 1975 & KUZ Z167 Topotype & AB663661 & AB698878 & AB679704 & AB679705 & AB828561 \\
\hline O. ketagalan Nakano and Lai, 2012 & KUZ Z208 Holotype & AB704785 & AB704786 & AB704787 & AB828582 & AB828563 \\
\hline O. koikei Nakano, 2012 & KUZ Z156 Holotype & AB698883 & AB698882 & AB679688 & AB679689 & AB828560 \\
\hline O. masaakikuroiwai Nakano, 2014 & KUZ Z694 Holotype & AB938003 & AB938013 & AB938006 & AB937997 & AB938016 \\
\hline O. mononoke Nakano, 2012 & KUZ Z224 Holotype & AB698868 & AB698869 & AB698866 & AB698867 & AB828564 \\
\hline O. nakahamai Nakano, 2016 & KUZ Z1672 Holotype & LC106330 & LC106332 & LC106331 & LC106329 & LC106333 \\
\hline O. naraharaetmagarum Nakano, 2016 & KUZ Z1652 Holotype & LC087143 & LC087145 & LC087144 & LC087142 & LC087146 \\
\hline O. octonaria Oka, 1895 & KUZ Z181 Topotype & $\mathrm{AB} 698870$ & AB698871 & AB679708 & AB679709 & AB828562 \\
\hline O. okanoi Nakano, 2016 & KUZ Z1671 Holotype & LC106341 & LC106343 & LC106342 & LC106340 & LC106344 \\
\hline O. shimadae Nakano, 2011 & KUZ Z128 Holotype & AB663663 & AB698875 & AB679676 & AB679677 & AB828557 \\
\hline O. tsushimensis Nakano, 2011 & KUZ Z134 Holotype & AB663653 & AB698872 & AB679662 & AB679663 & AB828554 \\
\hline O. whitmani Oka, 1895 & KUZ Z45 Topotype & AB663657 & $\mathrm{AB} 698874$ & AB679668 & AB679669 & AB828556 \\
\hline O. yamaneae Nakano, 2016 & KUZ Z1678 Holotype & LC106349 & LC106351 & LC106350 & LC106348 & LC106352 \\
\hline \multicolumn{7}{|l|}{ Outgroup } \\
\hline Erpobdella japonica Pawłowski, 1962 & KUZ Z178 & AB663648 & AB698879 & AB679654 & AB679655 & AB828542 \\
\hline Gastrostomobdella monticola Moore, 1929 & UNIMAS/A3/BH01/10 & AB663649 & AB698880 & AB679656 & AB679657 & AB828543 \\
\hline Mimobdella japonica Blanchard, 1897 & KUZ Z179 & AB663650 & AB698881 & AB679658 & AB679659 & AB828544 \\
\hline Odontobdella blanchardi (Oka, 1910) & KUZ Z180 & AB663651 & AB938012 & AB938004 & AB937995 & AB938014 \\
\hline
\end{tabular}

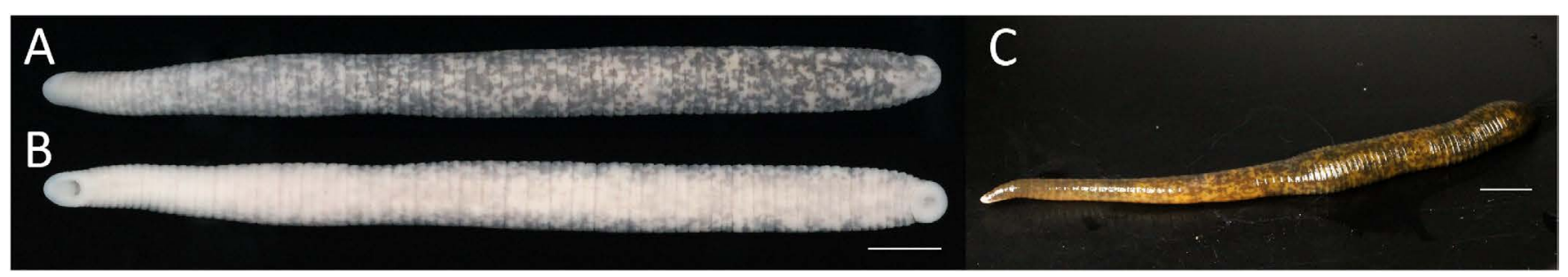

Fig. 2. Orobdella meisai sp. nov., holotype, KUZ Z1917. A, dorsal view; B, ventral view; C, dorsal view of live animal. Scale bars: $5 \mathrm{~mm}$.

(KUZ Z1910, Z1914, and Z1915 were dissected).

Description. Body firm and muscular, elongate, with constant width in caudal direction, dorsoventrally compressed, BL $62.5 \mathrm{~mm}$, BW $4.7 \mathrm{~mm}$ (Fig. 2A, B). Caudal sucker ventral, slightly elliptic, CL $2.7 \mathrm{~mm}$, CW $2.9 \mathrm{~mm}$ (Figs 2B, 3D).

Somite I completely merged with prostomium (Fig. 3A). Somites II (=peristomium), III and IV uniannulate (Fig. $3 \mathrm{~A}$ ); somite II not separated from somite I. Somite V biannulate, $(\mathrm{a} 1+\mathrm{a} 2)=\mathrm{a} 3$; $\mathrm{a} 3$ forming posterior margin of oral sucker (Fig. 3A, B). Somites VI and VII triannulate, $\mathrm{a} 1=\mathrm{a} 2=\mathrm{a} 3$ (Fig. 3A, B). Somites VIII-XXV quadrannulate, $\mathrm{a} 1=\mathrm{a} 2=\mathrm{b} 5=\mathrm{b} 6$ (Fig. $3 \mathrm{~A}-\mathrm{E}$ ). Somite XXVI triannulate, $\mathrm{a} 1>\mathrm{a} 2<\mathrm{a} 3$; $\mathrm{a} 3$ being ventrally last complete annulus (Fig. 3C, D). Somite XXVII uniannulate with slight dorsolateral furrow on respective sides (Fig. 3C). Anus behind somite
XXVII; post-anal annulus absent (Fig. 3C).

Somite X b5 and somite XIII a2, respectively, being first and last annuli of clitellum (Fig. 3E).

Male gonopore in somite XI b5/b6 (Fig. 3E). Female gonopore slightly posterior to anterior margin of somite $\mathrm{XIII}$ a1, inconspicuous, located posterior to gastropore (Fig. 3E, F). Gonopores separated by $5+1 / 4$ annuli (Fig. 3E).

Anterior ganglionic mass in somite VI a2 and a3. Ganglion VII in a1 and a2. Ganglia VIII-XIX, of each somite, in a2 (Fig. 4B). Ganglia XX-XXII, of each somite, in a1 and a2. Ganglion XXIII in a2. Ganglia XXIV-XXV, of each somite, in a1 and a2. Ganglion XXVI in somite XXV b6. Posterior ganglionic mass in somite XXVI a2 and a3.

Eyes in 3 pairs, 1st pair dorsally on anterior margin of somite III, 2nd and 3rd pairs dorsolaterally on posterior mar- 

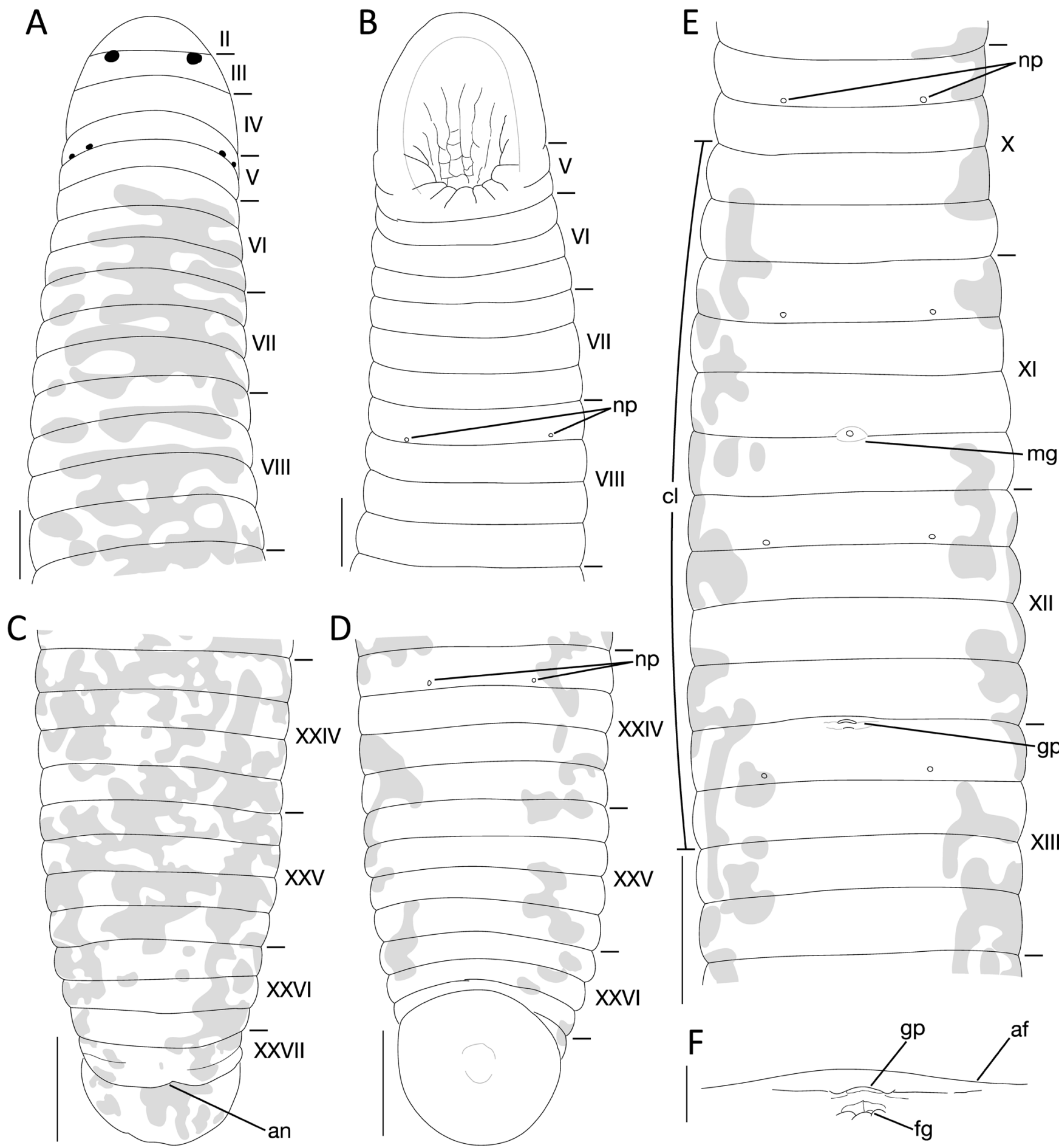

Fig. 3. Orobdella meisai sp. nov., holotype, KUZ Z1917. A, dorsal view of somites I-VIII; B, ventral view of somites I-VIII; C, dorsal view of somites XXIV-XXVII and caudal sucker; D, ventral view of somites XXIV-XXVI and caudal sucker; E, ventral view of somites X-XIII; F ventral view of gastropore and female gonopore. Scale bars: $1 \mathrm{~mm}(\mathrm{~A}, \mathrm{~B}) ; 2 \mathrm{~mm}(\mathrm{C}-\mathrm{E}) ; 0.25 \mathrm{~mm}(\mathrm{~F})$. Abbreviations: af, annular furrow; an, anus; $\mathrm{cl}$, clitellum; fg, female gonopore; gp, gastropore; $\mathrm{mg}$, male gonopore; $\mathrm{np}$, nephridiopore.

gin of somite V (a1+a2) (Fig. 3A). Papillae numerous, minute, hardly visible, on row on every annulus.

Nephridiopores in 17 pairs, each situated ventrally at posterior margin of al of each somite in somites VIII-XXIV (Fig. 3B, D, E).

Pharynx agnathous, euthylaematous, reaching to somite XV b5 (Fig. 4A). Crop tubular, acecate, reaching to somite
XXI a2. Gastropore conspicuous, ventral, slightly posterior to anterior margin of somite XIII a1 (Fig. 3E, F). Gastroporal duct rudimentary tubular, reaching to somite $\mathrm{XV}$ a1/a2 (Fig. 4A); its pore opening to crop hardly detectable. Intestine tubular, acecate, reaching to somite XXIV a1/a2. Rectum tubular, thin-walled, straight.

Testisacs multiple (Fig. 4B); on right side, in somite XVIII 
A
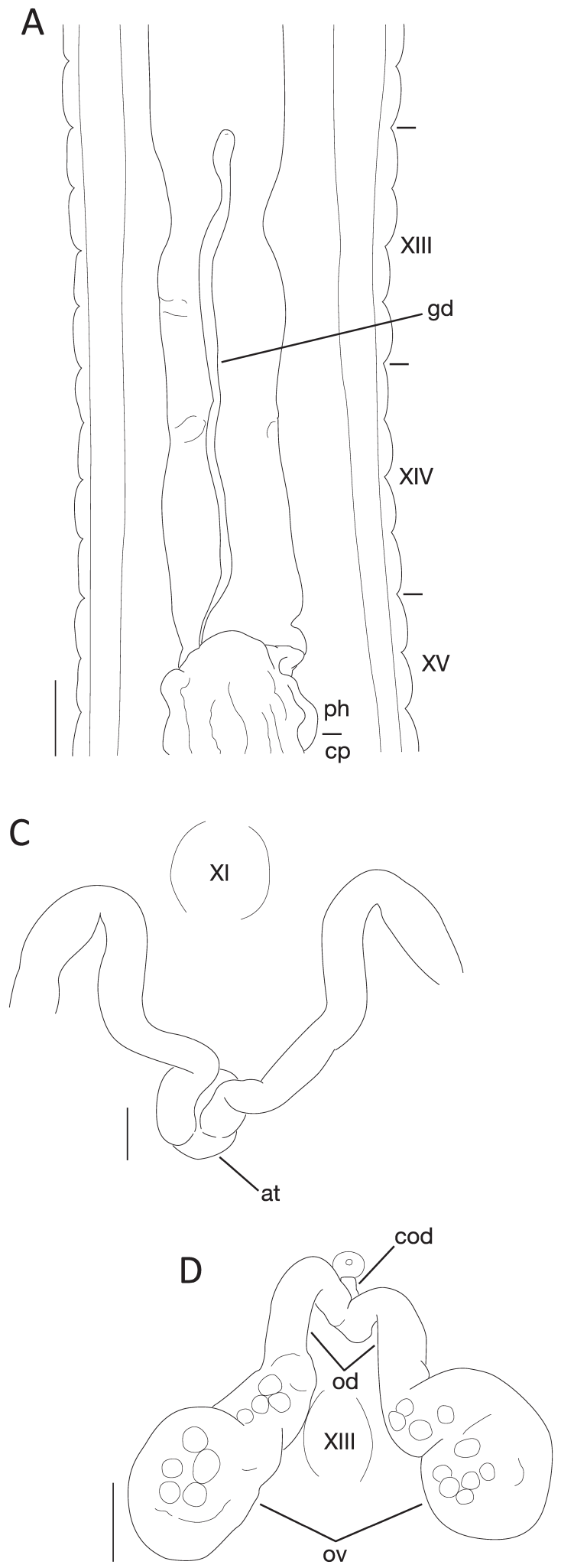

B

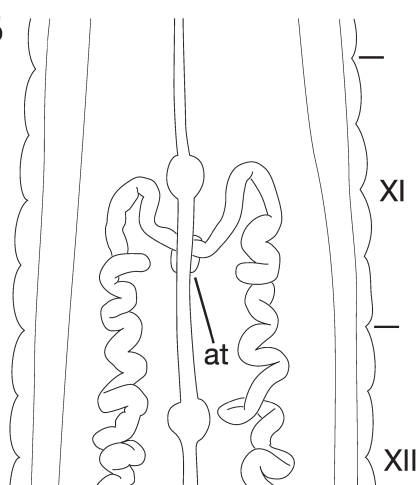

XII

XIII

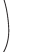

XIV

XV

\section{ed}

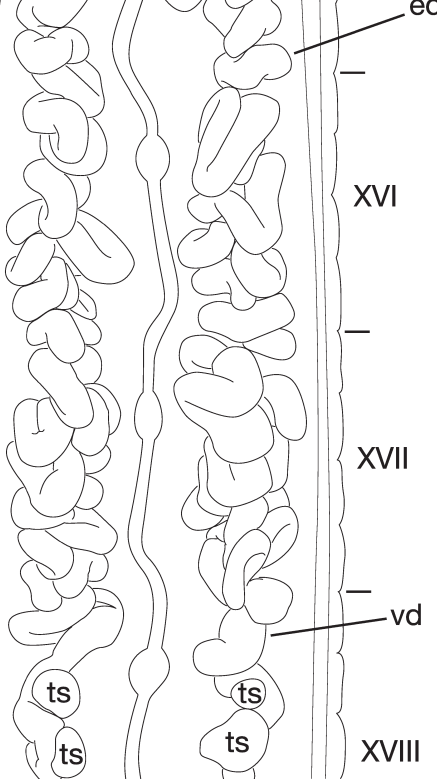

Fig. 4. Orobdella meisai sp. nov., holotype, KUZ Z1917. A, ventral view of gastroporal duct; B, dorsal view of reproductive system including ventral nervous system; C, dorsal view of male atrium including position of ganglion XI; D, dorsal view of female reproductive system including position of ganglion XIII. Scale bars: $1 \mathrm{~mm}(\mathrm{~A}) ; 2 \mathrm{~mm}(\mathrm{~B}) ; 0.25 \mathrm{~mm}(\mathrm{C}) ; 0.5 \mathrm{~mm}$ (D). Abbreviations: at, atrium; cod, common oviduct; cp, crop; ed, ejaculatory duct; gd, gastroporal duct; od, oviduct; ov, ovisac; ph, pharynx; ts, testisac; vd, vas deference.

a2 to somite XXV a2, in total $\sim 40$ testisacs, 4 in XVIII, 5 in XIX, 6 in XX, 6 in XXI, 5 in XXII, 5 in XXIII, 6 in XXIV, 3 in XXV; on left side, in somite XVIII a2 to somite XXIV b6, in total $\sim 35$ testisacs, 3 in XVIII, 4 in XIX, 7 in XX, 5 in XXI, 5 in XXII, 5 in XXIII, 6 in XXIV. Paired vasa deferentia thick (Fig. 4B). Epididymis absent. Paired ejaculatory 
ducts in somite XI a2 to somite XVIII a1 (Fig. 4B); coiled in position posterior to ovisacs; each duct crossing ventrally beneath each ovisac, then coiled in position anterior to ovisacs; each winding from respective junction with vas deferens, narrowing toward atrium with pre-atrial loop extending to middle of somite XI a2. Atrial cornu absent. Atrium small, globular, in somite XI b5 and b6 (Fig. 4B, C). Penis sheath and penis absent.

Paired ovisacs globular, in somite XIII a2 and b5 (Fig. 4B, D). Oviducts thin-walled (Fig. 4D); both oviducts converging in to common oviduct in somite XIII a1; dorsal surface of junction of both oviducts covered with ventral nerve cord. Common oviduct thin-walled, short, directly descending to female gonopore (Fig. 4D).

Variation. Measurements (mean $\pm 1 \mathrm{SD}$, followed by ranges in parentheses; $n=13$, including holotype): $\mathrm{BL}$ $48.9 \pm 16.3 \mathrm{~mm} \quad(27.4-73.1 \mathrm{~mm})$, BW $4.2 \pm 1.5 \mathrm{~mm}$ (2.1$7.2 \mathrm{~mm})$, CL $2.1 \pm 0.68 \mathrm{~mm}(1.2-3.0 \mathrm{~mm}), \mathrm{CW} 2.5 \pm 0.79 \mathrm{~mm}$ (1.4-4.2 mm). Somite XXVI a3 sometimes with slight dorsal furrow, or dorsolateral furrow on respective sides. Somite XXVII generally uniannulate without secondary furrow, or rarely biannulate. First pair of eyes rarely dorsally on posterior margin of somite II, or on somites II/III; small unpaired eye dorsally on left posterior margin of somite III (KUZ Z1912). Pharynx reaching to somite XV b5/b6-b6. Crop reaching to somite XXI a1-a2. Gastroporal duct reaching to somite XV a2-b5/b6. Intestine reaching to somite XXIII b5/ b6-somite XXIV a2/b5. Testisacs; right side, 34-42 sacs in somite XVII b5-b6 to somite XXV a1-a2; left side, 36-42 sacs in somite XVII b5-b6 to somite XXIV b6-somite XXV a2. Paired ejaculatory ducts in somite XI a2 to somite XVII a2/b5-b5. Paired ovisacs in somite XIII a2, or in somite XIII $\mathrm{a} 2$ and $\mathrm{b} 5$.

Coloration. In life, dorsal-to-lateral surface yellowish brown with irregular brownish markings without distinct pattern (Fig. 2C); ventral surface brownish white with irregular dark markings, ventral median region rarely with markings. Color faded in preservative, but irregular markings on surface remain (Fig. 2A, B).

Distribution. This species was collected only from its type locality. The present locality is the southernmost habitat within the known range of Orobdella species.

Natural history. This species was found curled up under rocks in moist mountainous habitats, and is thus terrestrial. A mature individual bearing a slight clitellum (=holotype) was collected on 9 March 2017. This finding suggests that the reproductive season of this species begins in early-to-middle March.

Molecular analyses results. The $\mathrm{ML}$ tree (ln $L=$ -28606.84; Fig. 5) for estimating the phylogenetic position of the new species had an identical topology to that of the BI tree (mean $\ln L=-28193.30$; not shown). Orobdella meisai belonged to a well-supported clade ( $\mathrm{BS}=100 \%, \mathrm{PP}=1.0$ ) containing the other eight species inhabiting the western part of Honshu to Taiwan. The clade was divided into two subclades: a well-supported lineage $(\mathrm{BS}=99 \%, \mathrm{PP}=1.0)$ consisted of four species, i.e., O. esulcata Nakano, 2010, O. naraharaetmagarum Nakano, 2016, O. kanaekoikeae Na-

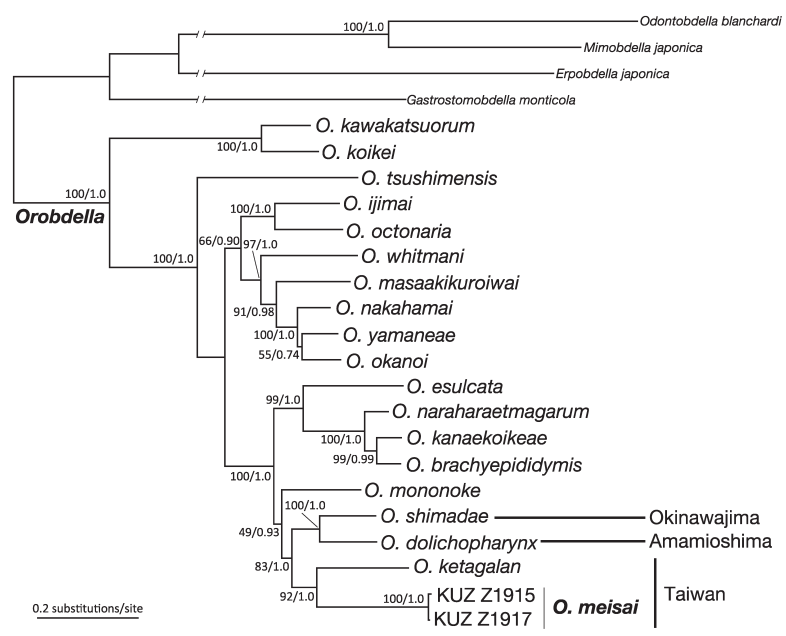

Fig. 5. Maximum likelihood tree for $5207 \mathrm{bp}$ of nuclear $18 \mathrm{~S}$ rRNA and histone $\mathrm{H} 3$ and mitochondrial COI, tRNA ${ }^{\mathrm{Cys}}$, tRNA ${ }^{\mathrm{Met}}$, $12 \mathrm{~S}$ rRNA, tRNA ${ }^{\mathrm{Val}}, 16 \mathrm{~S}$ rRNA, tRNA ${ }^{\text {Leu }}$ and ND1 markers. Numbers on nodes represent bootstrap values for maximum likelihood and Bayesian posterior probabilities.

kano, 2017 and O. brachyepididymis Nakano, 2016, inhabiting the western part of Honshu, Shikoku and Kyushu islands of Japan; another lineage was not fully supported in the ML tree $(\mathrm{BS}=49 \%, \mathrm{PP}=0.92)$, comprising three species, i.e., $O$. mononoke Nakano, 2012, O. shimadae Nakano, 2011 and O. dolichopharynx Nakano, 2011, from the Ryukyu Islands, and the two Taiwanese O. ketagalan and O. meisai. The monophyly of O. shimadae, O. dolichopharynx, O. ketagalan and $O$. meisai was supported $(\mathrm{BS}=83 \%, \mathrm{PP}=1.0)$. The two Ryukyu species, O. shimadae inhabiting Okinawajima island, and O. dolichopharynx known from Amamioshima island, formed a fully supported clade ( $\mathrm{BS}=100 \%, \mathrm{PP}=1.0$ ). Monophyly of the Taiwanese O. ketagalan and O. meisai was also well-supported ( $\mathrm{BS}=92 \%, \mathrm{PP}=1.0)$.

The ND1 sequences (LC314421 and LC314426) obtained from the holotype and paratype of $O$. meisai exhibit unique genetic variations compared with those of the other known Orobdella leeches. The ND1 sequences of $O$. meisai lack 97th-111th and 249th-260th bp positions in those of the other congeners. Since those missing positions are counted from the first position of the ND1 sequences, the former deletion indicates that the 33rd-37th codons are missing from the O. meisai ND1 sequences, and the latter deletion shows that the $83 \mathrm{rd}-87$ th codons are compacted into a single DNA triplet.

Etymology. The specific name is from a Japanese word meisai (=camouflage) referring to the dorsal coloration of the new species. The specific name is thus treated as indeclinable.

Remarks. Orobdella meisai clearly belongs to Orobdella, because it possesses the generic diagnostic characteristics defined by Nakano (2016a): post-anal annulus absent; male gonopore in posterior part of somite XI; female gonopore in anterior part of somite XIII; gonopores separated by more than one full somite; pharynx agnathous euthylaematous; gastropore in anterior part of somite XIII; gastroporal duct 
Table 2. Comparisons of morphological characters between Orobdella meisai sp. nov. and ten quadrannulate congeneric species.

\begin{tabular}{|c|c|c|c|c|c|c|c|c|}
\hline Species & $\begin{array}{l}\text { Body } \\
\text { length }\end{array}$ & $\begin{array}{l}\text { Somite } \\
\text { IV }\end{array}$ & $\begin{array}{l}\text { Somite } \\
\text { XXV }\end{array}$ & $\begin{array}{l}\text { Annuli between } \\
\text { gonopores }\end{array}$ & Pharynx length & Gastroporal duct & Epididymides & Atrial cornua \\
\hline O. meisai & middle & 1 & 4 & $5+1 / 4$ & to posterior XV & rudimentary tubular & absent & absent \\
\hline O. brachyepididymis & small & 1 & 4 & $1 / 2+4[+(<1 / 2)]$ & to anterior XIV & tubular & $\mathrm{XX}$ to XXI & small, ovate \\
\hline O. esulcata & middle & 1 & 4 & $2 / 3+4+1 / 3$ & to anterior to posterior XIV & $\begin{array}{l}\text { tubular, but bulbous at } \\
\text { junction with gastropore }\end{array}$ & $\mathrm{XVI}$ to XX & developed, ovate \\
\hline O. kanaekoikeae & small & 1 & 4 & $1 / 2+4+1 / 2$ & to posterior XIII to anterior XIV & bulbous & XIV to XVIII & developed, ovate \\
\hline O. kawakatsuorum & middle & 2 & 4 & 6 & to middle to posterior XIV & simple tubular & $\mathrm{XVI}$ to XVII & undeveloped \\
\hline O. ketagalan & middle & 1 & 4 & $1 / 2+4+1 / 2$ & to posterior XIV & simple tubular & absent & undeveloped \\
\hline O. koikei & small & 1 & 3 & $1 / 2+4+1 / 2$ & to posterior XIII to anterior XIV & bulbous & $\mathrm{XV}$ to $\mathrm{XX}$ & developed, ovate \\
\hline O. masaakikuroiwai & small & 1 & 4 & $1 / 2+4+1 / 2$ & to anterior to middle XIV & bulbous & XVI to XVIII & developed, ovate \\
\hline O. naraharaetmagarum & small & 1 & 4 & $1 / 2+4+1 / 2$ & to posterior XIII & bulbous & $\mathrm{XV}$ to $\mathrm{XX}$ & developed, ovate \\
\hline O. tsushimensis & middle & 1 & 4 & $1 / 2+5$ & to posterior XIII to posterior XIV & bulbous & XVII to XIX & developed, ovate \\
\hline O. whitmani & middle & 1 or 2 & 4 & $1 / 2+4+1 / 2$ & to anterior to posterior of XIV & bulbous & XVI to XVIII & developed, ovate \\
\hline
\end{tabular}

lying on female organ; testisacs multiple; male atrium in posterior part of somite XI, without penis sheath or penis; ovisacs globular in somite XIII; female median reproductive system essentially lacking.

According to taxonomic studies (Nakano 2010, 2011b, 2012a; Nakano and Lai 2012; Nakano 2014; Nakano and Seo 2014; Nakano 2016a, b, 2017b), the new species is distinguishable from the ten quadrannulate species (O. brachyepididymis, O. esulcata, O. kanaekoikeae, O. kawakatsuorum Richardson, 1975, O. ketagalan, O. koikei Nakano, 2012, O. masaakikuroiwai Nakano, 2014, O. naraharaetmagarum, O. tsushimensis, and O. whitmani Oka, 1895) by the following combination of characters (Table 2): body length, annulation of somites IV and XXV, number of annuli between gonopores, pharynx length, gastroporal duct, epididymidal lengths and atrial cornua. Orobdella meisai can clearly differ from these known quadrannulate species in having $5+1 / 4$ annuli between the gonopores, the pharynx reaching to the posterior part of somite $\mathrm{XV}$, the rudimentary tubular gastroporal duct, and in lacking atrial cornua in the male median reproductive system.

The new species is obviously distinguished from the six sexannulate species, i.e., O. dolichopharynx, O. ijimai Oka, 1895, O. mononoke, O. okanoi Nakano, 2016, O. shimadae and O. yamaneae Nakano, 2016, and two octannulate species, i.e., O. nakahamai Nakano, 2016 and O. octonaria Oka, 1895 , by its mid-body somites that are quadrannulate.

\section{Discussion}

Orobdella meisai possesses a rudimentary gastroporal duct and an undeveloped male median reproductive system without atrial cornua. These characteristics are congruent with the recent finding that the Orobdella gastroporal duct is a secondary copulatory organ that receives a spermatophore (Nakano 2017b); a leech spermatophore is secreted from the male atrium (Brumpt 1900). It remains uncertain whether the gastroporal duct of $O$. meisai plays a role as a spermatophore receptor. However, it is highly possible that the rudimentary gastroporal duct of $O$. meisai has lost its function, and that this species transfers spermatozoa directly to the female organ.

Undeveloped gastroporal duct and male atrium are shared characteristics within a clade comprising four Orobdella species distributed in the Ryukyu Islands and Taiwan. Orobdella shimadae and O. dolichopharynx, which are respectively indigenous to Okinawajima and Amamioshima islands, possess a rudimentary gastroporal duct, and they completely lack an atrial cornu (Nakano 2011a). Although the Taiwanese O. ketagalan bears atrial cornua and a functional gastroporal duct, these organs are generally undeveloped (Nakano and Lai 2012). Since O. mononoke and the other phylogenetically related species, e.g., O. esulcata, O. kanaekoikeae and O. naraharaetmagarum, possess a developed gastroporal duct and atrial cornua (Nakano 2010, 2012b, 2016b, 2017b), the undeveloped gastroporal duct and atrium may be synapomorphic characters within the clade containing O. shimadae, O. dolichopharynx, O. ketagalan and O. meisai. Moreover, the pharynx of O. shimadae, O. dolichopharynx, and O. meisai, of which the gastroporal duct is vestigial, is relatively longer than those of the close congeners with a developed gastroporal duct (Nakano 2011a, 2012b; Nakano and Lai 2012). The pharyngeal elongation and degeneration of the gastroporal duct within Orobdella species may correlate with each other.

The obtained phylogenies showed that $O$. meisai is genetically highly diverged from $O$. ketagalan compared with the phylogenetic relationships of $O$. shimadae and O. dolichopharynx. These relationships suggest that the diversification of the Taiwanese Orobdella species had occurred prior to the speciation between O. shimadae and O. dolichopharynx. A biogeographical study with divergence time estimates of Orobdella species will help to improve our understanding of the evolutional history of this East-Asian specific terrestrial leech group.

\section{Acknowledgments}

The authors are grateful to Mr Fu-Sheng Huang, Mr WeiRen Liang and Mr Kao-Shr Shiang for providing specimens of the new species. We are also grateful to Dr Ko Tomikawa (Hiroshima University) for his generous assistance with our 
filed survey in 2017, and to two anonymous reviewers and Dr Nozomu Muto (Tokai University) for their constructive comments on this manuscript. This study was financially supported by JSPS KAKENHI Grant numbers JP26840127 and JP15J00720.

\section{References}

Brumpt, É. 1900. Reproduction des Hirudinées. Mémoires de la Société Zoologique de France 13: 286-430.

Gilyarov, M. S., Lukin, E. I., and Perel, T. S. 1969. The first terrestrial leech-Orobdella whitmani Oka (Hirudinel, Herpobdellidae)-in the fauna of the USSR: A Tertiary relict of forests of the southern Maritime Territory. Doklady Akademii Nauk SSSR 188: 235-237. [In Russian]

Katoh, K. and Standley, D. M. 2013. MAFFT multiple sequence alignment software version 7: improvements in performance and usability. Molecular Biology and Evolution 30: 772-780.

Lanfear, R., Frandsen, P. B., Wright, A. M., Senfeld, T., and Calcott, B. 2017. PartitionFinder 2: New methods for selecting partitioned models of evolution for molecular and morphological phylogenetic analyses. Molecular Biology and Evolution 34: 772-773.

Moore, J. P. 1927. The segmentation (metamerism and annulation) of the Hirudinea. Pp. 1-12. In: Harding, W. A. and Moore, J. P. The Fauna of British India, including Ceylon and Burma. Hirudinea. Taylor \& Francis, London.

Nakano, T. 2010. A new species of the genus Orobdella (Hirudinida: Arhynchobdellida: Gastrostomobdellidae) from Kumamoto, Japan, and a redescription of $O$. whitmani with the designation of the lectotype. Zoological Science 27: 880-887.

Nakano, T. 2011a. Redescription of Orobdella ijimai (Hirudinida: Arhynchobdellida: Gastrostomobdellidae), and two new species of Orobdella from the Ryukyu Archipelago, Japan. Zootaxa 2998: $1-15$.

Nakano, T. 2011 b. A new species of Orobdella (Hirudinida: Arhynchobdellida: Gastrostomobdellidae) from Tsushima Island, Japan. Species Diversity 16: 39-47.

Nakano, T. 2012a. A new species of Orobdella (Hirudinida, Arhynchobdellida, Gastrostomobdellidae) and redescription of $O$. kawakatsuorum from Hokkaido, Japan with the phylogenetic position of the new species. ZooKeys 169: 9-30.

Nakano, T. 2012b. A new sexannulate species of Orobdella (Hirudinida, Arhynchobdellida, Orobdellidae) from Yakushima Island, Japan. ZooKeys 181: 79-93.

Nakano, T. 2014. A new quadrannulate species of Orobdella (Hirudinida, Arhynchobdellida, Orobdellidae) from central Honshu, Japan. ZooKeys 445: 57-76.

Nakano, T. 2016a. Four new species of the genus Orobdella from Shikoku and Awajishima island, Japan (Hirudinida, Arhynchobdellida, Orobdellidae). Zoosystematics and Evolution 92: 79-102.

Nakano, T. 2016b. A new quadrannulate species of Orobdella (Hirudinida, Arhynchobdellida, Orobdellidae) from western Honshu, Japan. ZooKeys 553: 33-51.

Nakano, T. 2017a. Diversity of leeches from Japan: recent progress in macrophagous and blood-feeding taxa. Pp. 319-340. In: Motokawa, M. and Kajihara, H. (Eds) Species Diversity of Animals in Japan. Springer Japan, Tokyo.

Nakano, T. 2017b. A new species of Orobdella (Hirudinida: Arhynchobdellida: Orobdellidae) from Japan reveals the function of the Orobdella gastroporal duct. Zoological Science 34: 161-172.

Nakano, T. and Lai, Y.-T. 2012. A new species of Orobdella (Hirudinida, Arhynchobdellida, Orobdellidae) from Taipei, Taiwan. ZooKeys 207: 49-63.

Nakano, T. and Seo, H.-Y. 2012. First record of Orobdella tsushimensis (Hirudinida: Arhynchobdellida: Orobdellidae) from Korea (Gageodo Island) and its molecular phylogenetic position within the genus. Species Diversity 17: 235-240.

Nakano, T. and Seo, H.-Y. 2014. First record of Orobdella tsushimensis (Hirudinida: Arhynchobdellida: Gastrostomobdellidae) from the Korean Peninsula and molecular phylogenetic relationships of the specimens. Animal Systematics, Evolution and Diversity 30: 87-94.

Rambaut, A. and Drummond, A. J. 2013. Tracer v 1.6. Available at http://tree.bio.ed.ac.uk/software/tracer/ (24 May 2015)

Ronquist, F., Teslenko, M., van der Mark, P., Ayres, D. L., Darling, A., Höhna, S., Larget, B., Liu, L., Suchard, M. A., and Huelsenbeck, J. P. 2012. MrBayes 3.2: Efficient Bayesian phylogenetic inference and model choice across a large model space. Systematic Biology 61: 539-542.

Stamatakis, A. 2014. RAxML version 8: a tool for phylogenetic analysis and post-analysis of large phylogenies. Bioinformatics 30: 13121313. 